\title{
An Alternative Therapy for Patients with Hepatic Impairment?
}

\author{
Su-Pin $\mathrm{Choo}^{\mathrm{a}}$ Alan P. Venook \\ ${ }^{a}$ Medical Oncology, National Cancer Centre, Singapore \\ a Division of Medical Oncology, UCSF Comprehensive Cancer Center, San Francisco, CA, USA
}

Patients with advanced cancer in the setting of liver dysfunction pose a real challenge for physicians, as many cancer chemotherapeutic agents undergo hepatic metabolism and their administration to patients with hepatic impairment often leads to compromise of patient safety. A large proportion of patients with colorectal cancer either present with or develop liver metastases and as a result, many of them have suboptimal liver function [1].

In this issue of ONKOLOGIE Moosmann et al. [2] present a case of a patient with diffuse liver metastases secondary to carcinoma of the colon who was treated successfully with the combination of bevacizumab and cetuximab despite having abnormal liver function parameters. This patient had previously failed capecitabine and oxaliplatin combination chemotherapy, making irinotecan-based chemotherapy with or without a targeted agent the standard second-line choice. However, this patient's bilirubin level was markedly elevated at $12.8 \mathrm{mg} / \mathrm{dl}$, aspartate transaminase was elevated 8 times the upper limit of normal (ULN) at $390 \mathrm{U} / 1$ and the alanine transaminase was mildly elevated. Irinotecan's main metabolite, SN-38, is cleared primarily via liver glucuronidation and in the biliary system and several studies have shown that patients with bilirubin levels greater than 1.5 times ULN and transaminases greater than 5 times ULN were most susceptible to irinotecan toxicities. [3, 4]. Thus, irinotecan was not a viable option for this patient and most oncologists, faced with a similar situation, would probably have offered supportive care.

In this case, the authors opted to treat this patient with cetuximab and bevacizumab combined and achieved reduction in liver metastases. This was associated with a decrease of the bilirubin level to $1.9 \mathrm{mg} / \mathrm{dl}$ after 8 weeks of therapy, eventually rendering the patient amenable to further treatment with irinotecan-based chemotherapy.

Despite limited data on their use in colon cancer, the combined use of an epidermal growth factor (EGFR) inhibitor, cetuximab, with the vascular endothelial growth factor (VEGF) inhibitor bevacizumab is logical. Cetuximab as monotherapy in refractory colon cancer has modest activity with partial response rates of about $10 \%$ and stable disease in about $30 \%[5,6]$ while bevacizumab alone achieves a stable disease rate of $29 \%$ and partial response rate of about 3\% [7]. HER-1/EGFR is involved in angiogenesis [8] and its inhibition has been shown to cause VEGF down-regulation [9]. Furthermore, studies have shown that blockade of VEGF may also inhibit HER-1/EGFR autocrine signaling [10], thus suggesting the synergistic benefit of combining a VEGF inhibitor and an EGFR inhibitor. Several preclinical studies have investigated the anti-tumor activity of this dual blockade of EGFR and VEGF in colon cancer $[11,12]$.

To our knowledge, there have only been 2 studies that have looked at the combination of bevacizumab and cetuximab in colorectal cancer in the clinical setting. The phase II BOND II trial [13] randomized patients with irinotecan-refractory colorectal cancer to receive cetuximab $\left(250 \mathrm{mg} / \mathrm{m}^{2}\right.$ weekly $)$ and bevacizumab (5 mg/kg every other week) with or without irinotecan. Preliminary results showed that patients receiving cetuximab and bevacizumab achieved a partial response rate of $20 \%$ with time to treatment progression of 5.6 months, which was better than historical controls of patients receiving cetuximab alone $(\mathrm{p}<0.01)$. The group receiving cetuximab, bevacizumab and irinotecan also had a better partial response of $37 \%$ and time to progression of 7.9 months compared to historical controls who received cetuximab and inrinotecan alone $(\mathrm{p}<0.01)$. No unexpected adverse effects were observed in either group of patients. This demonstrated the feasibility of this combination and its benefit in irinotecan-refractory, bevacizumab-naïve colorectal patients, with normal liver function. Similarly, results from a phase II study evaluating the combination of cetuximab and bevacizumab in colorectal patients who had failed irinotecan, oxaliplatin and fluoropy-

\begin{tabular}{ll}
\hline KARGER & ( 2007 S. Karger GmbH, Freiburg \\
Fax +4976145207 14 & Accessible online at: \\
$\begin{array}{l}\text { E-mail Information@Karger.de } \\
\text { www.karger.com }\end{array}$ & www.karger.com/onk
\end{tabular}

Alan P. Venook, M.D. 
rimidine-based chemotherapy were presented recently [14]. In this small study, bevacizumab was given at $10 \mathrm{mg} / \mathrm{kg}$ every 2 weeks, while cetuximab was given per previous study. Amongst 14 patients evaluable for response, there was one partial response and the median time to progression was 2.4 months. While these studies suggest that this combination has activity in refractory colorectal cancer, they do not address the issue of patients with hepatic impairment.

Neither bevacizumab nor cetuximab have been reported to undergo hepatic metabolism. The use of bevacizumab in patients with liver dysfunction has not been studied [15]. In a population pharmacokinetics analysis, there was no correlation found between hepatic dysfunction and cetuximab pharmacokinetics [16]. Cetuximab has been used as a single agent in a phase II study in advanced hepatocellular carinoma where $40 \%$ of the subjects had Childs-Pugh B liver cirrhosis. There was a non-significant trend towards higher mean serum trough cetuximab levels and a delay in achieving steady-state in those with mild to moderate hepatic impairment although this was not associated with increased toxicities. In this case report, the patient appeared to tolerate the combination of bevacizumab and cetuximab (which were given at the recom- mended full doses) well with no significant toxicities except grade 3 skin rash.

Current clinical trials in colorectal cancer typically exclude patients with less than normal liver function status. Ongoing studies on advanced colorectal cancer patients with normal liver function will eventually tell us the optimal way of combining cetuximab and bevacizumab and other targeted therapy. With the ready availability of effective non-chemotherapy agents which do not rely on hepatic metabolism, more options are potentially available for cancer patients with hepatic impairment. As this case report illustrates, it is not unreasonable to offer targeted agents like cetuximab combined with bevacizumab (with careful monitoring) in a patient with advanced colon cancer and significant liver impairment, who cannot otherwise receive standard chemotherapy regimens. There is no doubt that more studies with targeted therapies need to be directed towards cancer patients with organ dysfunction to determine dosing and toxicities, and perhaps, in the future, this group of patients may no longer be relegated to receive 'just supportive care' but may be deemed fit enough to actually receive some effective life prolonging therapy.

\section{References}

1 Burke D, Allen-Mersh TG: Colorectal liver metastases. Postgrad Med J 1996;72(850):464-9.

2 Moosmann N, Laessig D, Michaely HJ, Schulz C, Heinemann V: Effective second-line treatment with cetuximab and bevacizumab in a patient with hepatic metastases of colorectal cancer and hyperbilirubinemia. Onkologie 2007;30:509-512.

$\checkmark 3$ Schaaf LJ, Hammond LA, Tipping SJ, Goldberg RM, Goel R, Kuhn JG, Miller LL, Compton LD, Cisar LA, Elfring GL, Gruia G, McGovren JP, Pirotta N, Yin D, Sharma A, Duncan BA, Rothenburg ML: A phase 1 and pharmacokinetic study of intravenous irinotecan in refractory solid tumor patients with hepatic dysfunction. Clin Cancer Res 2006;12(12):3782-91.

4 Venook AP, Enders Klein C, Fleming G, Hollis D, Leichman CG, Hohl R, Byrd J, Budman D, Villalona M, Marshall J, Rosner GL, Ramirez J, Kastrissios H, Ratain MJ: A phase I and pharmacokinetic study of irinotecan in patients with hepatic or renal dysfunction or with prior pelvic radiation: CALGB 9863. Ann Oncol 2003;14:1783-90.

5 Saltz LB, Meropol NJ, Loehrer PJ Sr, Needle MN, Kopit J, Mayer RJ: Phase II trial of cetuximab in patients with refractory colorectal cancer that expresses the epidermal growth factor receptor. J Clin Oncol 2004;22(7):1201-8.

6 Lenz HJ, Van Cutsem E, Khambata-Ford S, Mayer RJ, Gold P, Stella P, Mirtsching B, Cohn AL, Pippas AW, Azarnia N, Tsuchihashi Z, Mauro DJ, Rowinsky EK: Multicenter phase II and translational study of cetuximab in metastatic colorectal carcinoma refractory to irinotecan, oxaliplatin, and fluoropyrimidines. J Clin Oncol 2006;24(30):4914-21.
7 Giantonio BJ, Catalano PJ, Meropol NJ, O’Dwyer PJ, Mitchell EP, Alberts SR, Schwartz MA, Benson AB: High-dose bevacizumab improves survival when combined with FOLFOX4 in previously treated advanced colorectal cancer: Results from the Eastern Cooperative Oncology Group (ECOG) study E3200. ASCO Annual Meeting Proceedings. J Clin Oncol 2005; 23(16S)2.

8 Kim SJ, Uehara H, Karashima T, Shepherd DL, Killion JJ, Fidler IJ: Blockade of epidermal growth factor receptor signaling in tumor cells and tumorassociated endothelial cells for therapy of androgen-independent human prostate cancer growing in the bone of nude mice. Clin Cancer Res 2003;9:1200-1210.

- Hirata A, Ogawa S, Kometani T, Kuwano T, Naito S, Kuwano M, Ono M: ZD1839 (Iressa) induces antiangiogenic effects through inhibition of epidermal growth factor receptor tyrosine kinase. Cancer Res 2002;62:2554-2560.

10 Ciardiello F, Caputo R, Damiano V, Fontanini G, Caputo R, Pomatico G, De Placido S, Bianco AR, Mendelsohn J, Tortora G: Antitumor effects of ZD6474, a small molecule vascular endothelial growth factor receptor tyrosine kinase inhibitor, with additional activity against epidermal growth factor receptor tyrosine kinase. Clin Cancer Res 2003;9:1546-1556.
1 Ciardiello F, Bianco R, Damiano V, Fontanini G, Caputo R, Pomatico G, De Placido S, Bianco AR, Mendelsohn J, Tortora G: Antiangiogenic and antitumor activity of anti-epidermal growth factor receptor C225 monoclonal antibody in combination with vascular endothelial growth factor antisense oligonucleotide in human GEO colon cancer cells. Clin Cancer Res 2000;6:3739-3747.

12 Shaheen RM, Ahmad SA, Liu W, Reinmuth N, Jung YD, Tseng WW, Drazan KE, Bucana CD, Hicklin DJ, Ellis LM: Inhibited growth of colon cancer carcinomatosis by antibodies to vascular endothelial and epidermal growth factor receptors. Br J Cancer 2001;85:584-589.

13 Saltz LB, Lenz H, Hochster H, Wadler S, Hoff P, Kemeny N, Hollywood E, Gonen M, Wetherbee S, Chen H: Randomized Phase II trial of cetuximab/ bevacizumab/irinotecan (CBI) versus cetuximab/ bevacizumab $(\mathrm{CB})$ in irinotecan-refractory colorectal cancer. 2005 ASCO Annual Meeting Proceedings. J Clin Oncol 2005;23(16S):3508.

14 Souglakos J, Kalbakis K, Vamvakas N, Kalykaki A, Kotsakis A, Agelaki S, Karampeazis A, Gioulbasanis J, Georgoulias V: Cetuximab plus bevacizumab in patients (pts) with metastatic colorectal cancer (mCRC) who have failed on irinotecan, oxaliplatin and fluoropyrimidines-based chemotherapy. 2007 ASCO Annual Meeting Proceedings Part I. J Clin Oncol 2007;25(18S):14576.

15 Avastin (Bevacizumab) Drug Label, Genentech; www.fda.gov/cder/drug/infopage/avastin/default.htm.

16 Erbitux (Cetuximab) Drug Label, Imclone Systems Inc. $w w w . f d a . g o v / c d e r / d r u g / i n f o p a g e / e r b i t u x / d e f a u l t$ .htm. 